\title{
Learning how to live with a child with ADHD was a long and arduous process
}

Kendall J. Outlasting disruption: the process of reinvestment in families with ADHD children. Qual Health Res 1998 Nov;8:839-57.

\section{Question}

How do families with children who have attention deficit hyperactivity disorder (ADHD) manage the ongoing and persistent difficulties caused by their children's ADHD symptoms?

\section{Design}

Grounded theory.

\section{Setting}

USA.

\section{Participants}

15 families (14 white) with $\geqslant 1$ child with ADHD between the ages of 6 and 18 years. The ADHD child and $\geqslant 1$ parent had to be willing to participate. 15 mothers, 10 fathers, 20 children with ADHD (mean age 11 y, 16 boys), and 14 siblings without ADHD (mean age $11 \mathrm{y}, 8$ boys) were interviewed. 5 families had a single mother, 7 had both biological parents living at home, and 3 had a biological mother and a stepfather.

\section{Methods}

109 individual and family open ended interviews, each lasting 30-90 minutes, were done in the home. Each person was asked to describe what it was like to live with $\mathrm{ADHD}$ or with an ADHD family member and how their family functioned. Second individual and family interviews were done 8-12 weeks later.

\section{Main findings}

Outlasting disruption was the core variable. Family life was described as chaotic, conflictual, and exhausting. Disruptive behaviours were aggression, out of control hyperactivity, emotional and social immaturity, academic underachievement and learning problems, family conflicts, negative peer interactions, and isolation and rejection from the extended family. Parents regained control over their lives (process of reinvestment) using a 3 step model (making sense, recasting biography, and relinquishing the good ending).
Making sense had 4 categories. Sinking in dealt with being able to admit a problem existed. Believing dealt with coming to terms with the child's identified problem and working towards normal functioning. Wearing out was a cyclical process of getting stuck, giving up, recharging, burning out, and getting stuck again. Transferring responsibility included relinquishing the idea that normal functioning was possible.

Recasting biography involved parents examining their lives and developing new directions. Its categories were remembering their own childhood difficulties; grieving the past and current situations, and the child's inability to become a strong and self confident adult; individuating when the mother realised she had to "separate" from the child (often a son); and restoring self in which parents put energies back into themselves and felt comfortable with who they were.

Relinquishing the good ending was the final process. It involved letting go of the belief that a child with $\mathrm{ADHD}$ was just like everyone else and moving beyond grief. The categories were deintegrating stigma by examining their own beliefs about ADHD, gaining perspective by changing old beliefs and fostering an emotional acknowledgment of the disorder, and letting go of the anticipated normal child. Once these processes were complete, parents were able to come to terms with the child's disability and engage in reinvestment in the "real" children, family, other children, marriage, and themselves.

\section{Conclusion}

Parenting a child with ADHD was a long and arduous process, and parents outlasted the disruption by making sense of the disorder, recasting biography, and relinquishing the good ending.

Source of funding: National Institute of Child Health and Human Development.

For correspondence: Dr J Kendall, Oregon Health Sciences University, School of Nursing, $3181 \mathrm{SW}$ Sam Jackson Road, Portland, OR 97201-3098, USA. Fax +1 5034943878.

\section{Commentary}

ADHD, a disorder involving inattentiveness, overactivity, and impulsivity, has been the subject of recent debate in child and adolescent mental health. Much of the debate has centred on establishing diagnostic criteria and on specific interventions; Kendall's study, in contrast, centres on the experiences of those who are part of a family which has a child with ADHD.

Although Kendall identifies a specific process and 3 constituent subprocesses in the families studied, this is not the main strength of the study. Its main strength lies in the way in which it persuasively reminds the reader that the real life experiences of those living with a specific mental health problem are equally effective in informing practice as are more formal sources such as textbooks. As Kendall herself points out, all too often the focus of any intervention with families similar to those described in the study is on training family members to be better carers or parents. Issues important to the families themselves, such as offering physical or emotional support, respite, or family centred mental health services, are rarely given the attention they deserve.

Because the study gives us insight into the experiences of only a few families with a child with $\mathrm{ADHD}$, the identification of specific processes is only useful if it is set to inform rather than prescribe. Moreover, as with any research, the study raises more questions than answers:

- Are the predominantly white, "high functioning and well educated" families included in the study typical of other families with ADHD children?
- Are these families different from other families caring for a family member with special needs?

- Are similar processes evident in families that appear to be relatively stress free?

- What about families who do not outlast disruption-families who are unable to cope with the burden of caring for a family member with special needs?

In summary, Kendall's paper is a most welcome contribution to a body of literature that is woefully lacking in carer and user centred perspectives.

Steven Pryjmachuk, RMN, MSc Nurse Tutor (Mental Health) School of Nursing, Midwifery, and Health Visiting

University of Manchester, Manchester, UK 